\title{
CONTROLADORIA E CONTABILIDADE GERENCIAL: DEZ ANOS DE PRODUÇÃO CIENTÍFICA
}

\section{CONTROLLERSHIP AND MANAGEMENT ACCOUNTING: TEN YEARS OF SCIENTIFIC PRODUCTION}

Henrique César Melo Ribeiro

Professor Adjunto pela Universidade Federal do Piauí, Campus, Ministro Reis Velloso

Parnaíba, PI, Brasil

Email: hcmribeiro@gmail.com

\section{RESUMO}

O objetivo deste estudo foi analisar a produção científica da área temática Controladoria e Contabilidade Gerencial divulgada no congresso Anpcont de 2007 a 2016. Metodologicamente, utilizou-se as técnicas de análise bibliométrica e de rede social. Foram encontrados e analisados 246 estudos. Foi feita a análise destes estudos, mediante os seguintes índices: autores, rede de coautoria, instituições, rede social das instituições, e temas abordados. Os principais resultados foram: Ilse Maria Beuren, Carlos Eduardo Facin Lavarda. Andson Braga de Aguiar, Carlos Alberto Diehl e Fábio Frezatti foram os autores mais profícuos. As instituições mais produtivas foram: FURB, USP, UFSC, Unisinos e Fucape. Em relação as redes de coautoria e das instituições, observou-se em ambas uma baixa densidade. $\mathrm{E}$ os temas mais publicados foram: gestão de custos, processo orçamentário, contabilidade gerencial, controladoria, controle gerencial, balanced scorecard, gestão pública e governança corporativa

Palavras-chave: Controladoria e contabilidade gerencial. Produção científica. Anpcont. Bibliometria. Rede social.

\section{ABSTRACT}

The objective of this study was to analyze the scientific production of the thematic area Controllership and Management Accounting published in the Anpcont congress from 2007 to 2016. Methodologically, the techniques of bibliometric analysis and social network were used. 246 studies were found and analyzed. These studies were analyzed using the following indexes: authors, co-authoring network, institutions, social network of the institutions, and themes covered. The main results were Ilse Maria Beuren, Carlos Eduardo Facin Lavarda. Andson Braga de Aguiar, Carlos Alberto Diehl and Fábio Frezatti were the most prolific authors. The most productive institutions were: FURB, USP, UFSC, Unisinos and Fucape. In relation to co-authoring networks and institutions, a low density was observed in both. And the most published topics were cost management, budget process, managerial accounting, control, management control, balanced scorecard, public management and corporate governance.

Keywords: Controllership and management accounting. Scientific production. Anpcont. Bibliometrics. Social network. 


\section{INTRODUÇÃO}

A análise da produção científica é fator importante para o entendimento e compreensão do conhecimento científico, promovendo o aperfeiçoamento e fomento da ciência (NASCIMENTO; PEREIRA; TOLEDO FILHO, 2010), como, por exemplo, as Ciências Contábeis (MURCIA; ROSA; BORBA, 2013) no Brasil (SOARES; RICHARTZ; MURCIA, 2013). Realça-se que a produção científica é realizada por pesquisadores e instituições de ensino superior (IESs) às quais tais autores estão atrelados (WALTER; BACH, 2013).

A produção científica pode ser vista sob duas óticas: (i) prestação de contas do pesquisador para com a sociedade, que de certa forma, financia a sua pesquisa; e (ii) é entendida e compreendida como a troca de informação, conhecimentos e saberes entre autores, mediante os diversos meios de comunicação, sejam eles formais e/ou informais. E com isso, ao realizar estudos científicos e evidenciar seus achados, os acadêmicos exercem atividades preponderantes para o fomento, aperfeiçoamento, difusão, disseminação e socialização do conhecimento científico (CORREIA; ALVARENGA; GRACIA, 2012).

No que tange as divulgações formais e/ou informais Arboit e Bufrem (2011) afirmam que os congressos científicos são vistos como meios de comunicação mais informais e, com isso, mais ágeis na manifestação e na troca do conhecimento científico. Ressalta-se que os estudos submetidos aos eventos científicos passam por avaliação alargada do comitê científico, comumente composto por acadêmicos da área. Esse processo de avaliação é parecido ao dos artigos de periódicos científicos, apesar da publicação nestas revistas serem, em geral, mais valorizada (GUFFEY; HARP, 2016), pois costumam contemplar importantes contribuições, tendências para o desenvolvimento da área contábil como produto acabado de pesquisa (CARNEGIE; NAPIER, 2017).

Versa-se também que os eventos científicos aceitam também o contato informal entre os pesquisadores que atuam no mesmo campo do saber. Com isso, ocorre agrupamento de pesquisadores com interesse comum, influenciando na troca e compartilhamento de informações e conhecimento e, posteriormente na criação de valor científico, por meio de novas parcerias ou grupos de pesquisa, uma vez que a troca de informações e conhecimentos se dá de forma mais ativa do que em os outros meios de evidenciação científica, apesar do seu escopo informal (ARBOIT; BUFREM, 2011).

Entende-se que o desígnio desses congressos científicos é agenciar o diálogo entre acadêmicos e pesquisadores, oportunizar a difusão, socialização e discussão de temas embrionários, emergentes, maduros e legitimados, estabelecer ligação entre teoria e prática e permitir a criação de ideias, agregando valor acadêmico para futuras pesquisas científicas nas áreas do conhecimento, como é o caso da contabilidade (SCHMITZ et al., 2015).

$\mathrm{Na}$ área contábil, a publicação científica é disseminada por meio de vários congressos, destacando-se, no Brasil, o Congresso Anpcont, promovido anualmente, desde 2007 (SCHMITZ et al., 2015), que é um evento de grande relevância acadêmico científica da Associação Nacional de Programas de Pós-Graduação em Ciências Contábeis (SILVA; WANDERLEY; SANTOS, 2010), e tem como objetivo socializar as pesquisas (DE LUCA et al., 2011). buscando estabelecer uma conexão entre estes estudos acadêmicos e as aplicações nas organizações, permitindo a disseminação mais densa dos diversos enfoques em várias nuances no bojo 
destes estudos realizados na área do conhecimento das Ciências Contábeis (SILVA; WANDERLEY; SANTOS, 2010).

O citado congresso é dividido em cinco áreas temáticas, são elas: Mercados Financeiro, de Crédito e de Capitais (MFC), Educação e Pesquisa em Contabilidade (EPC), Contabilidade Aplicada ao Setor Público e ao Terceiro Setor (CPT), Contabilidade para Usuários Externos (CUE) e Controladoria e Contabilidade Gerencial (CCG) (ANPCONT, 2017). Em relação a área temática Controladoria e Contabilidade Gerencial, observa-se que ela está entre as mais dominantes no congresso Anpcont (VENDRAMIN, 2014; SCHMITZ et al., 2015; COSENZA et al., 2016).

A controladoria tem sido abordada no Brasil como disciplina acadêmica independente de outras, como contabilidade gerencial, contabilidade de custos, controle gerencial (LUNKES et al., 2012), governança corporativa (NASCIMENTO; BIANCHI; TERRA, 2007; VAN DER POLL; MTHIYANE, 2018). Pode-se considerar com isso a controladoria como sinônimo de contabilidade gerencial (LUNKES et al., 2012). Diante do panorama, se faz relevante analisar a produção científica da área temática Controladoria e Contabilidade Gerencial divulgada no congresso Anpcont de 2007 a 2016. Neste contexto, esboça-se a questão de pesquisa que norteará este estudo: Qual é o perfil e o comportamento da produção científica da área temática Controladoria e Contabilidade Gerencial divulgada no congresso Anpcont de 2007 a $2016 ?$

Diante do exposto, ressalva-se que alguns estudos já investigaram tal área temática, contudo, não individualmente, são eles: Souza et al. (2008), Silva, Wanderley e Santos (2010), Cruz et al. (2011), Cabral, Siqueira e Batista (2011), Cunha, Dal Magro e Dias (2012), Miranda et al. (2013), Amaral et al. (2014), Schmitz et al. (2015), Cosenza et al. (2016). Já os estudos de: Beuren, Schlindwein e Pasqual (2007), Luciani, Cardoso e Beuren (2007), Laudelino, Navarro e Beuren (2010), Peleias et al. (2010), Albuquerque et al. (2013) e Souza et al. (2013), focaram apenas o tema controladoria; e as pesquisas de: Nascimento, Junqueira e Martins (2010), Araújo e Silva (2010), Lunkes, Feliu e Rosa (2012), Oliveira e Boente (2012), Ribeiro e Espejo (2013), Schaltegger, Gibassier e Zvezdov (2013) e Lunkes et al. (2014) evidenciaram a temática contabilidade gerencial. E os estudos de: Costa (2010), Ribeiro (2013), Brizolla, Chiarello e Lavarda (2014) e Blonkoski, Antonelli e Bortoluzzi (2017) investigaram a temática Controladoria e Contabilidade Gerencial, porém, não focando o congresso Anpcont.

Diante disso, constata-se que nenhum destes, enfocou de maneira insólita, a área temática Controladoria e Contabilidade Gerencial evidenciada pelo evento Anpcont. Diante disso, versa-se e justificase a questão e o objetivo deste estudo, a fim de que a temática Controladoria e Contabilidade Gerencial evidenciada e publicada pelo evento Anpcont, seja conhecida no contexto acadêmico nacional, por meio dos indicadores biblimétricos e de rede social deste estudo. Diante disso, salienta-se que uma das formas de analisar a produção científica é com base nas técnicas de análise bibliométrica (CUNHA; CORREA; BEUREN, 2010) e de rede social (RIBEIRO, 2014; LOHMANN; EULERICH, 2017).

A justificativa para realização deste estudo é a necessidade de análise do estágio de desenvolvimento, difusão e socialização da área temática Controladoria e Contabilidade Gerencial, e por conseguinte do campo do conhecimento científico contabilidade, sob a ótica dos artigos da referida área temática, publicados no congresso Anpcont de 2007 a 2016. Outra justificativa é querer conhecer a heterogeneidade da produção científica da área temática Controladoria e Contabilidade Gerencial, por meio das redes de atores (autores e 
IESs), temas abordados, evidenciando assim, aspectos fundamentais para o entendimento e compreensão do perfil, comportamento e consequentemente evolução científica da área temática objeto de estudo.

Uma das contribuições aguardadas para este estudo é que os resultados da pesquisa auxiliem discussões, possibilitando assim uma melhor e mais robusta compreensão por parte de pesquisadores seniores e/ou iniciantes, docentes, e pelos Programas de Pós-Graduação Stricto Sensu da área contábil e afins, da importância e necessidade de refletir, ter ideias e insights acerca da temática em investigação e dos temas, por exemplo, que dela são oriundos, influenciando a posteiori em seu processo de estruturação, e/ou aperfeiçoamento da produção científica da área temática Controladoria e Contabilidade Gerencial.

Outra contribuição palpável é a evidenciação e disseminação de dados, informações e saberes contemporâneos acerca da temática ora analisada, possibilitando assim, uma agregação de valor acadêmico mediante conhecimentos não vistos ainda na literatura acadêmica contábil (CHAKRABORTY; CHIU; VASARHELYI, 2014) nacional, permitindo assim, criar um norte, em especial para novos acadêmicos que desejam ter um alicerce de conhecimento mais atualizado no que se concerne a área temática em avaliação.

Com isso, será criada a oportunidade de surgir novos projetos de pesquisa que se transformarão em trabalhos de conclusão de curso (monografias, dissertações e teses), artigos e livros, cunhando assim valor científico e influenciando no agregado de conhecimento e saberes para o campo temático Controladoria e Contabilidade Gerencial. Em decorrência disso, os temas abordados na Tabela 1, em especial, os que ainda são pouco estudados, ou seja, embrionários, poderão evoluir e, se desenvolverem, abrindo ainda mais o leque de possibilidades para o crescimento da Controladoria e da Contabilidade Gerencial no contexto acadêmico no Brasil.

Este estudo está dividido em cinco seções. A primeira abrange a introdução, com a questão, objetivo, justificativa e contribuição do estudo. Logo em seguida é abordada a fundamentação teórica, a qual focará no tema controladoria e contabilidade gerencial e sua produção científica. A terceira seção contempla os procedimentos metodológicos. A análise e discussão dos resultados é manifestada na quarta seção. E por fim, na seção cinco, é versada as conclusões, contribuições, limitações do estudo, e as sugestões para futuras pesquisas.

\section{FUNDAMENTAÇÃO TEÓRICA}

Esta seção aborda os temas contabilidade gerencial e controladoria, focando seus conceitos e algumas produções acadêmicas nacionais, sejam elas, conjuntas ou individuais respectivamente.

\section{Da contabilidade gerencial a controladoria: conceitos e produção científica}

A Contabilidade Gerencial é o ramo da Contabilidade que se ocupa das necessidades de informação dos gestores ou, de forma mais genérica, dos usuários internos das organizações (NECYK; FREZATTI, 2010), sendo assim considerada uma instituição dentro das empresas, estruturada por rotinas (BEUREN; MACOHON, 2011), e, sendo adequada, importante e necessária ao processo decisório empresarial (PADOVEZE, 1999; FREZATTI et al., 2007). Ressalta-se que os artefatos de contabilidade gerencial, como o orçamento, avaliação de desempenho e gestão de custos (REIS; TEIXEIRA, 2013), compõem o leque de 
rotinas de controle gerencial (ALMEIDA; STARKE JUNIOR; FREITAG, 2011), contribuindo na melhoria do processo decisório de gestão nas organizações (WERNKE, 2005; BITTI; AQUINO; CARDOSO, 2011; BEUREN; WIENHAGE, 2013).

Salienta-se que o alicerce conceitual da teoria da contabilidade gerencial (VAN DER MEERKOOISTRA; VOSSELMAN, 2012), é baseado na teoria neoclássica da firma (GUERREIRO et al., 2005), mas muitos pesquisadores observam que essa teoria não compõe fundamentação teórica única, adequado para esclarecer o desenvolvimento da Contabilidade Gerencial, pois, a teoria neoclássica foi aperfeiçoada por economistas para auxilia-los a prever comportamentos, efetuar trabalhos e análises em nível da indústria e do mercado. Não havia intenção de elucidar o comportamento de executivos dentro das empresas. A hipótese da racionalidade econômica dos indivíduos, que norteia a abordagem neoclássica, versa que os indivíduos estarão sempre tomando, particularmente, decisões racionais. Neste âmbito, todas as demais dimensões que cercam o ser humano, sobretudo a psicológica e a sociológica, são desconsideradas na análise econômica do modelo neoclássico (GUERREIRO, 2006).

Neste panorama, ressalta-se a Teoria Institucional, que aprovisiona uma perspectiva alternativa para a pesquisa das práticas da Contabilidade Gerencial. Esse aspecto leva o estudioso a uma análise detida da natureza das práticas vigentes na organização (GUERREIRO, 2006). A teoria institucional é uma abordagem sociológica que tem sido aplicada nas Ciências Contábeis. Essa teoria enfoca a contabilidade como uma instituição dentro da organização, ou seja, uma rotina desenvolvida por hábitos que dá sentido a determinado grupo de indivíduos. O ponto principal sobre o qual repousa a mencionada teoria é a ideia de hábitos de um grupo de indivíduos: a instituição é estruturada a partir de rotinas e as rotinas dependem de hábitos (GUERREIRO; FREZATTI; CASADO, 2006).

Isto posto, realça-se a pesquisa dos autores Guerreiro, Pereira e Rezende (2008) que identificaram características fundamentais de hábitos e rotinas da contabilidade gerencial. Realçam que a teoria institucional ensina que é necessário extinguir os velhos hábitos e rotinas para que as novas instituições prosperem. Os hábitos e rotinas são constantes, robustas e inconscientes, ou seja, são difíceis de serem transformados. Nessa conjuntura, o sucesso da prática de um novo modelo gerencial está diretamente associado à capacidade da firma de trocar envelhecidos hábitos por novos hábitos. A troca de hábitos passa, em primeiro lugar, pela definição de novos hábitos ambicionados alinhados com os novos fatores contingentes que se apresentam no ambiente empresarial. Logo após, é preciso arquitetar estratégias para enfrentar o desafio de alterações dos velhos hábitos e rotinas e estruturar as novas instituições, isto é, os novos conceitos da contabilidade gerencial.

Em suma, as rotinas contábeis podem ser caracterizadas como institucionalizadas (BEUREN; MACOHON, 2011) quando se tornam largamente aceitas na organização e são visualizadas como formas inquestionáveis de controle gerencial (ZUCCOLOTTO; SILVA; EMMENDOERFER, 2010). Com isso, a contabilidade gerencial como uma instituição corresponde a um conjunto de rotinas institucionalizadas e aceitas na organização, e tanto influencia outras instituições no âmbito da organização quanto é moldada por elas (BOFF; BEUREN; GUERREIRO, 2008).

Contudo, a Contabilidade Gerencial, em decorrência dos negócios e do mercado corporativo, evoluiu, transformando-se na Controladoria (MARTIN, 2002). Em outras palavras, verifica-se que a controladoria como área de responsabilidade dentro da organização se nutre de dados e informações suscitados pela 
contabilidade de custos, contabilidade financeira, contabilidade gerencial, dentre outras. A contabilidade gerencial, por sua vez, é a que proporciona maior aproximação com a controladoria em vista da conformidade entre seus objetivos e funções (BOFF; BEUREN; GUERREIRO, 2008).

Entende-se que a controladoria é um campo do saber que tenta concretizar um conjunto fundamental de funções (LUNKES et al., 2009) que norteiam e orientam os estudos e pesquisas cientificas na área e, consequentemente influenciando nas disciplinas acadêmicas e, concomitantemente na sua implementação, adoção e aplicação prática nas organizações (SARTORATTO; LUNKES; ROSA, 2016).

Com isso, compreende-se que a controladoria é responsável pela gestão econômica da organização, tendo um papel preponderante e decisivo na elaboração de modelos e sistemas de informação econômico/financeiro de apoio ao processo decisório, e consequentemente, para as tomadas de decisões, mediante a indicação de escolhas, com base em avaliações de desempenho necessárias na formulação de diretrizes para o planejamento estratégico da organização (FRANCISCHETTI; POKER JUNIOR; PADOVEZE, 2017).

Diante do contexto, ressalva-se que a controladoria age no controle gerencial, permitindo o monitoramento dos resultados econômicos/financeiros esperados, obtidos pela aplicação dos recursos disponíveis e divulgados pela estrutura patrimonial do ativo e passivo da organização, fomentando as oportunidades e mitigando as ameaças e os riscos inseridos no processo decisório de gestão (FRANCISCHETTI; POKER JUNIOR; PADOVEZE, 2017) e no planejamento (HEINZMANN; LAVARDA, 2011).

Lunkes, Gasparetto e Schnorrenberger (2010) analisaram comparativamente, visando identificar um conjunto básico de funções da controladoria, baseado em estudos empíricos sobre o tema nos Estados Unidos, Alemanha e Brasil. Os resultados evidenciam que as funções mais citadas são as de: elaboração e interpretação de relatórios, planejamento e controle contábil, respectivamente. Isso manifesta que a área de controladoria na prática tem atuado em atividades estratégicas nas organizações.

Cavalcante et al. (2012) descreveram as características da controladoria das maiores companhias com ações negociadas na BM\&FBovespa, segundo o ranking da Revista Exame Melhores e Maiores 2010. Os resultados encontrados pelos autores revelam a predominância da característica no que se refere a abrangência da controladoria no ambiente interno da empresa, interpretando a influência econômica dos eventos sobre o patrimônio, ao mesmo tempo em que desempenha, predominantemente, a função contábil gerencial.

Verifica-se com isso a relação próxima e intrínseca dos termos contabilidade gerencial e controladoria (PELEIAS et al., 2010; LUNKES et al., 2014). Para Padoveze (1999) a Controladoria, exercendo a função contábil gerencial, monitora adequadamente, o processo de geração de valor dentro da organização, por meio da: (i) adoção dos conceitos coerentes de aferição do lucro empresarial, que são resultados do conceito de lucro econômico/financeiro; e o auxílio às atividades operacionais no processo de geração de valor, mediante o sistema de informação contábil e gerencial. Diante disso, vê-se que a Controladoria e a Contabilidade Gerencial, mediante suas informações geradas internamente na organização, tem impacto importante na estratégia empresarial (SANTOS; ROCHA, 2011; BUI; DE VILLIERS, 2017), impactando com isso no desempenho empresarial (NASCIMENTO; GALLON, 2008). 
Contudo, versa-se que nos últimos anos, poucas pesquisas sobre a produção científica dos temas controladoria e contabilidade gerencial em conjunto foram manifestadas na literatura acadêmica nacional (Quadro 1). Foram elas: Costa (2010), Ribeiro (2013), Brizolla, Chiarello e Lavarda (2014) e Blonkoski, Antonelli e Bortoluzzi (2017).

Quadro 1: Estudos sobre a produção científica dos temas Contabilidade e ou Controladoria

\begin{tabular}{|c|c|}
\hline Estudos (autores) & Objetivo / Resultados / Conclusões \\
\hline Costa (2010) & $\begin{array}{l}\text { Analisou a produção do saber nos campos de controladoria e contabilidade } \\
\text { gerencial, utilizando por inspiração os procedimentos arqueológicos } \\
\text { foucaultianos, no período compreendido entre os anos de } 2007 \text { a } 2009 \text {, no } \\
\text { Brasil. constatou que autores mais prolíferos foram: Fábio Frezatti, Ana } \\
\text { Maria Roux Valentini Coelho César, Auster Moreira Nascimento e Carlos } \\
\text { Alberto Diehl. No que diz respeito aos temas mais abordados foram: } \\
\text { avaliação de desempenho e gestão de custos. }\end{array}$ \\
\hline Ribeiro (2013) & $\begin{array}{l}\text { Verificou as características da produção científica dos artigos publicados na } \\
\text { área temática controladoria e contabilidade gerencial no Congresso USP de } \\
\text { Controladoria e Contabilidade no período de } 2001 \text { a } 2011 \text {. Verificou que Ilse } \\
\text { Maria Beuren foi a autora mais prolífera. Universidade de São Paulo foi a } \\
\text { IES que mais publicou artigos. E os temas mais abordados foram: custos, } \\
\text { finanças, gestão organizacional, gestão governamental, sistema de } \\
\text { informação gerencial, contabilidade gerencial, informação contábil e } \\
\text { balanced scorecard. }\end{array}$ \\
\hline Brizolla, Chiarello e Lavarda (2014) & $\begin{array}{l}\text { Identificaram a sociometria e a bibliometria relacionada ao tema } \\
\text { controladoria e contabilidade gerencial nos artigos publicados em periódicos } \\
\text { internacionais. Observaram que as abordagens encontradas com maior } \\
\text { recorrência se relacionam ao desempenho gerencial e organizacional, } \\
\text { abordagens de práticas em contabilidade gerencial e a contabilidade como } \\
\text { ferramenta no desempenho gerencial. }\end{array}$ \\
\hline Blonkoski, Antonelli e Bortoluzzi (2017) & $\begin{array}{l}\text { Levantaram a situação atual de desenvolvimento da contabilidade gerencial } \\
\text { sob o viés da comunidade científica internacional. Os autores observaram } \\
\text { que os temas mais produzidos foram: planejamento estratégico, sistemas } \\
\text { de informações gerenciais, teoria da prática e teoria institucionais. Ainda } \\
\text { cabe mencionar que } 41 \% \text { dos estudos tiveram predominância da } \\
\text { abordagem econômica, } 39 \% \text { com a abordagem social e } 20 \% \text { com } \\
\text { abordagem comportamental. }\end{array}$ \\
\hline
\end{tabular}

Fonte: Elaborado pelo autor

De maneira geral, os estudos vislumbrados nesta seção, evidenciam as nuances do tema contabilidade gerencial sob óticas de estudos científicos diversos, contemplando e fazendo surgir sua diversidade como tema importante no contexto literário acadêmico nas Ciências Contábeis. Diante disso, versa-se que o presente estudo, enfocará, à luz do Anpcont e, utilizando indicadores bibliométricos e sociométricos contemporâneos e, com isso, realçando predominância e heterogeneidade do tema contabilidade gerencial, contribuindo posteriormente e consequentemente para melhor entendimento, compreensão e deste no meio acadêmico nacional, colaborando, para sua evolução e maior legitimidade para a área Contábil.

\section{PROCEDIMENTOS METODOLÓGICOS}

O objetivo deste estudo foi analisar a produção científica da área temática Controladoria e Contabilidade Gerencial divulgada no congresso Anpcont de 2007 a 2016. Para isso, metodologicamente utilizaram-se as técnicas de análise bibliométrica e de rede social.

A bibliometria é uma técnica quantitativa e estatística para mensurar indicadores de produção e disseminação do saber científico, bem como acompanhar o aperfeiçoamento de várias áreas científicas e as características de autoria, publicação e uso dos resultados de investigação. Diante disso, observa-se que a 
análise da produção científica é importante para o reconhecimento dos pesquisadores junto da comunidade científica, e é feita mediante a aplicação de diversos índices bibliométricos, que se dividem em indicadores de qualidade, importância e impacto científicos (COSTA et al., 2012). Importante para o entendimento e compreensão dos dados é conhecer as três leis que embasam a bibliometria (QUONIAM et al., 2001). Isto posto, Quoniam et al. (2001) evidenciam que:

1) Lei de Bradford (ou Lei da Dispersão): concentra sua descrição no comportamento repetitivo das ocorrências em um determinado campo do saber. Bradford escolheu o periódico para a sua análise, devido às suas características de incidência de assuntos e tendências, e observou que poucos periódicos produzem muitos artigos e muitos periódicos produzem poucos artigos.

2) Lei de Lotka: analisa a produção científica dos autores, ou seja, determina a contribuição de cada um deles para o progresso da ciência. A Lei de Lotka tem o seguinte enunciado: o número de autores que produzem $n$ trabalhos é proporcional a $1 / 1$ elevado a $n^{2}$ dos autores que produzem apenas um trabalho;

3) Lei de Zipf: é a chamada lei quantitativa fundamental da atividade humana. Subdivide-se na Primeira Lei de Zipf, que corresponde à freqüência das palavras que aparecem em um texto (número de ocorrência das palavras) (QUONIAM et al., 2001, p. 24).

Já a rede social é uma técnica epidemiológica que estuda as interações entre os atores (PÉRISSÉ; NERY, 2007) bem como a compleição e futuras configurações de determinados grupos de estudo (SOUZA et al., 2016), possuindo assim um papel preponderante como meio de difusão da informação, ideias, influências e conhecimentos (KIMURA; BASSO; MARTIN, 2008). Para este estudo, enfocará as seguintes estruturas de rede: densidade, centralidade de grau e de centralidade de intermediação (MELLO; CRUBELLATE; ROSSONI, 2010).

A densidade é determinada de acordo com o nível de interação entre as redes sociais de um determinado ator (CORREA; TEIXEIRA. 2015). Já a centralidade é o mais significativo indicador, a ser extraído de uma rede social, pois mostra as posições realizadas pelo ator na estrutura social da referida rede (MELO-SILVA, 2016). Existem várias proxies que servem para calcular a centralidade. Dentre essas, as mais comumente usadas são: (a) centralidade de grau (Degree); e a (b) centralidade de intermediação (Betweenness) (MENDES-DA-SILVA; ONUSIC; GIGLIO, 2013). A centralidade de grau é conseguida a partir do número de vínculos diretos que um ator possui e a medida de centralidade de intermediação considera se um ator ostenta, ou não, posição de intermediador na rede social (CRUZ et al., 2011).

Foi feita uma coleta de dados em artigos evidenciados no período de 2007 a 2016, o que corresponde a um levantamento longitudinal de 10 anos. Os dados foram coletados da Associação Nacional de Programas de Pós-Graduação em Ciências Contábeis (http://www.anpcont.org.br/congressos-anpcont). Os artigos envolvidos neste estudo foram especificamente da área temática Controladoria e Contabilidade Gerencial. Este processo consentiu identificar 246 estudos evidenciados no período 2007-2016.

Foi realizada a análise dos dados mediante os seguintes indicadores: (I) autores; (II) rede de coautoria; (III) IESs; (IV) rede social das IESs; e (V) temas abordados. Estes indicadores foram calculados e capturadas, utilizando os softwares UCINET 6 for Windows e Microsoft Excel 2007. 


\section{ANÁLISE E DISCUSSÃO DOS RESULTADOS}

Esta seção aborda a análise e discussão dos resultados dos 246 estudos identificados e evidenciados no período 2007-2016 no congresso Anpcont.

Os indicadores bibliométricos, no seu tocante, são utilizados para aferir a produtividade dos autores (COSTA et al., 2012). Sendo assim, a Figura 1 evidencia os 449 autores identificados nesta pesquisa, enfatizando os 20 mais profícuos.

Figura 1: Autores identificados na pesquisa

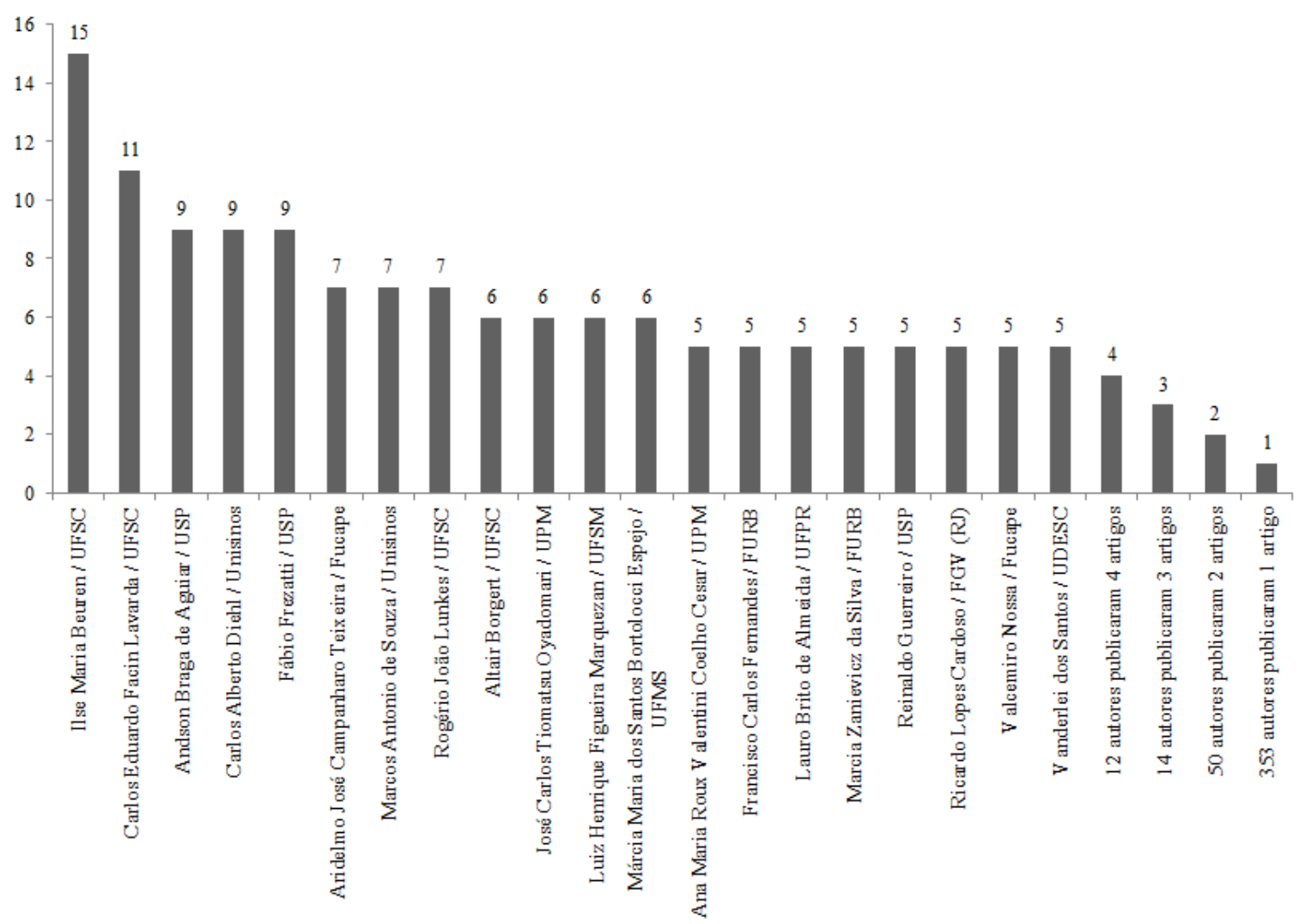

Fonte: Dados da pesquisa

Ilse Maria Beuren é a autora mais prolífera neste trabalho, com 15 publicações. Ribeiro (2013) corrobora com tal achado. Carlos Eduardo Facin Lavarda surge em segundo lugar com 11 divulgações. Com nove artigos aparecem os acadêmicos: Andson Braga de Aguiar, Carlos Alberto Diehl e Fábio Frezatti. Costa (2010) em seu estudo, também coloca em destaque os dois últimos pesquisadores como os mais profícuos no que se refere a área temática ora analisada. Com sete papers disseminados aparecem os acadêmicos: Aridelmo José Campanharo Teixeira, Marcos Antonio de Souza e Rogério João Lunkes. Já os estudiosos Altair Borgert, José Carlos Tiomatsu Oyadomari, Luiz Henrique Figueira Marquezan e Márcia Maria dos Santos Bortolocci Espejo, divulgaram seis investigações. E com cinco, surgem os investigadores: Ana Maria Roux Valentini Coelho Cesar, Francisco Carlos Fernandes, Lauro Brito de Almeida, Marcia Zanievicz da Silva, Reinaldo Guerreiro, Ricardo Lopes Cardoso, Valcemiro Nossa e Vanderlei dos Santos. 
De maneira geral, 20 autores publicaram de cinco a 15 artigos; 76 acadêmicos divulgaram de dois a quatro artigos; e a grande maioria, isto é, 353 investigadores publicaram uma investigação cada. Estes achados vão ao encontro da Lei de Lotka que mensura a produção científica dos autores (QUONIAM et al., 2001), e manifesta que poucos autores publicam muitos artigos e que muitos pesquisadores divulgam poucos estudos, mostrando, dessa forma, o nível de importância destes poucos estudiosos para a área ora investigada (RIBEIRO, 2013).

Entende-se que a análise longitudinal, é viável encontrar pesquisadores com publicações esporádicas, autores que deixam de divulgar no campo do saber, outros acadêmicos que passam a fazê-lo e outros que continuam por longo tempo evidenciando suas pesquisas nessa mesma área do conhecimento. Diante disso, a renovação da área do saber pode ser necessária, visto que a entrada de novos acadêmicos impacta na introdução de novas informações e conhecimentos (WALTER; BACH, 2013).

A Figura 2 visualiza a rede de coautoria dos 449 autores identificados neste estudo, colocando em evidência a centralidade de grau.

Figura 2: Rede de coautoria (centralidade de grau)

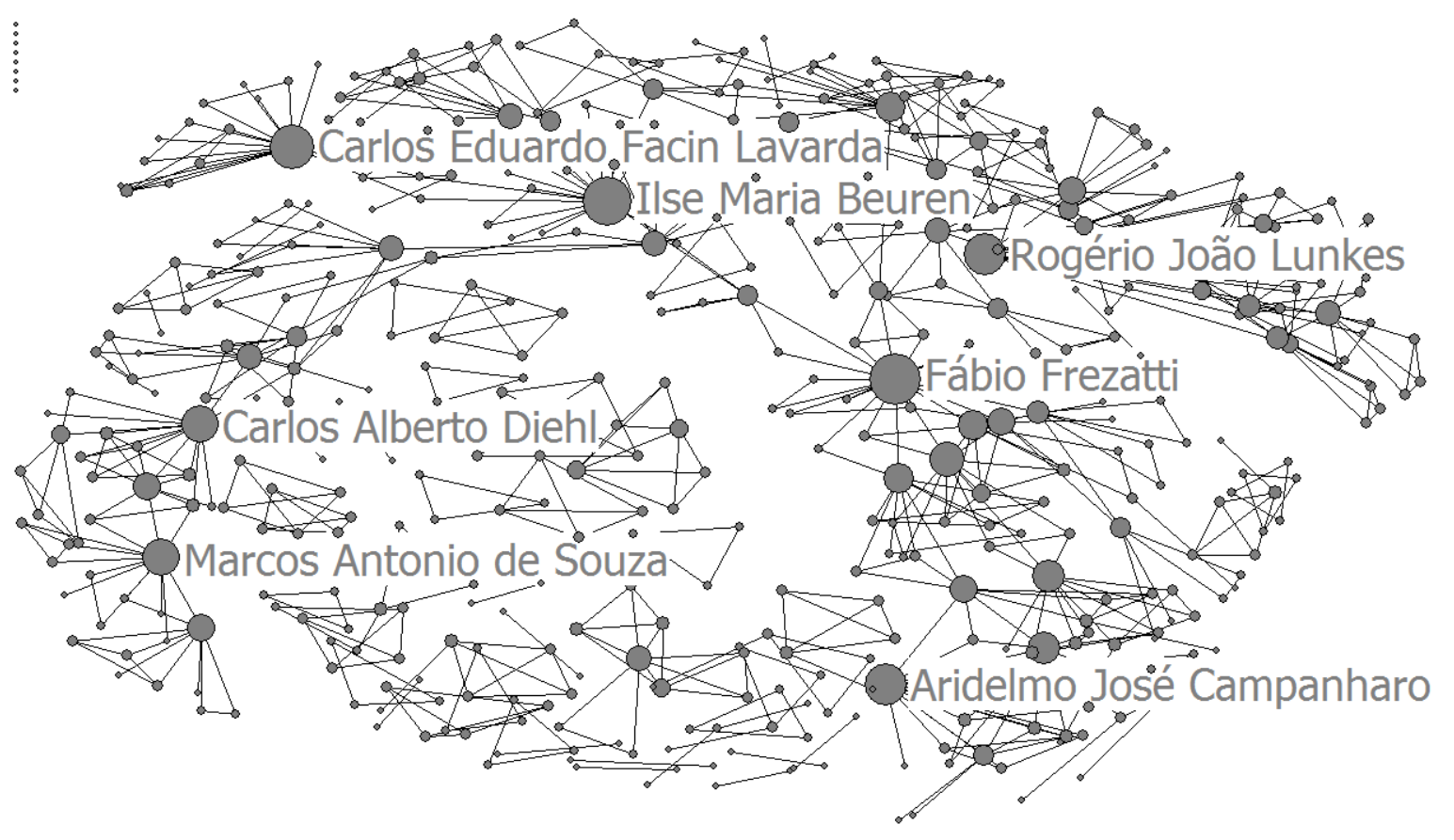

Fonte: Dados da pesquisa

A densidade da referida rede de coautoria é de 0,0069 , correspondendo apenas $0,69 \%$ das interações entre os autores que publicaram na área temática Controladoria e Contabilidade Gerencial. Tal resultado esboça que os relacionamento e colaborações entre os estudiosos da mencionada área podem evoluir muito mais, influenciando consequentemente na difusão, desenvolvimento e disseminação de temas que norteiam a área do conhecimento em investigação. A baixa conectividade entre os pesquisadores da rede social em analise, impacta diretamente na centralidade dos mesmos, como pode ser notada nesta seção, a qual a rede de coautoria com foco no degree, é dominada, ou melhor, é alicerçada por poucos acadêmicos, tornando-os 
relevantes na publicação de pesquisas sobre a área em foco, pois, estes possuem muitos vínculos de conexão com outros pesquisadores da rede (CRUZ et al., 2011; LOHMANN; EULERICH, 2017).

De acordo com suas respectivas centralidades, os autores são: Fábio Frezatti, Ilse Maria Beuren, Carlos Eduardo Facin Lavarda, Rogério João Lunkes, Aridelmo José Campanharo, Carlos Alberto Diehl e Marcos Antonio de Souza. É interessante notar que, destes sete pesquisadores, todos aparecem entre os oito mais profícuos deste trabalho, o que ratifica o realce e a envergadura destes na difusão, desenvolvimento e disseminação da área temática Controladoria e Contabilidade Gerencial divulgada no congresso Anpcont de 2007 a 2016.

Figura 3: Rede de coautoria (centralidade de intermediação)

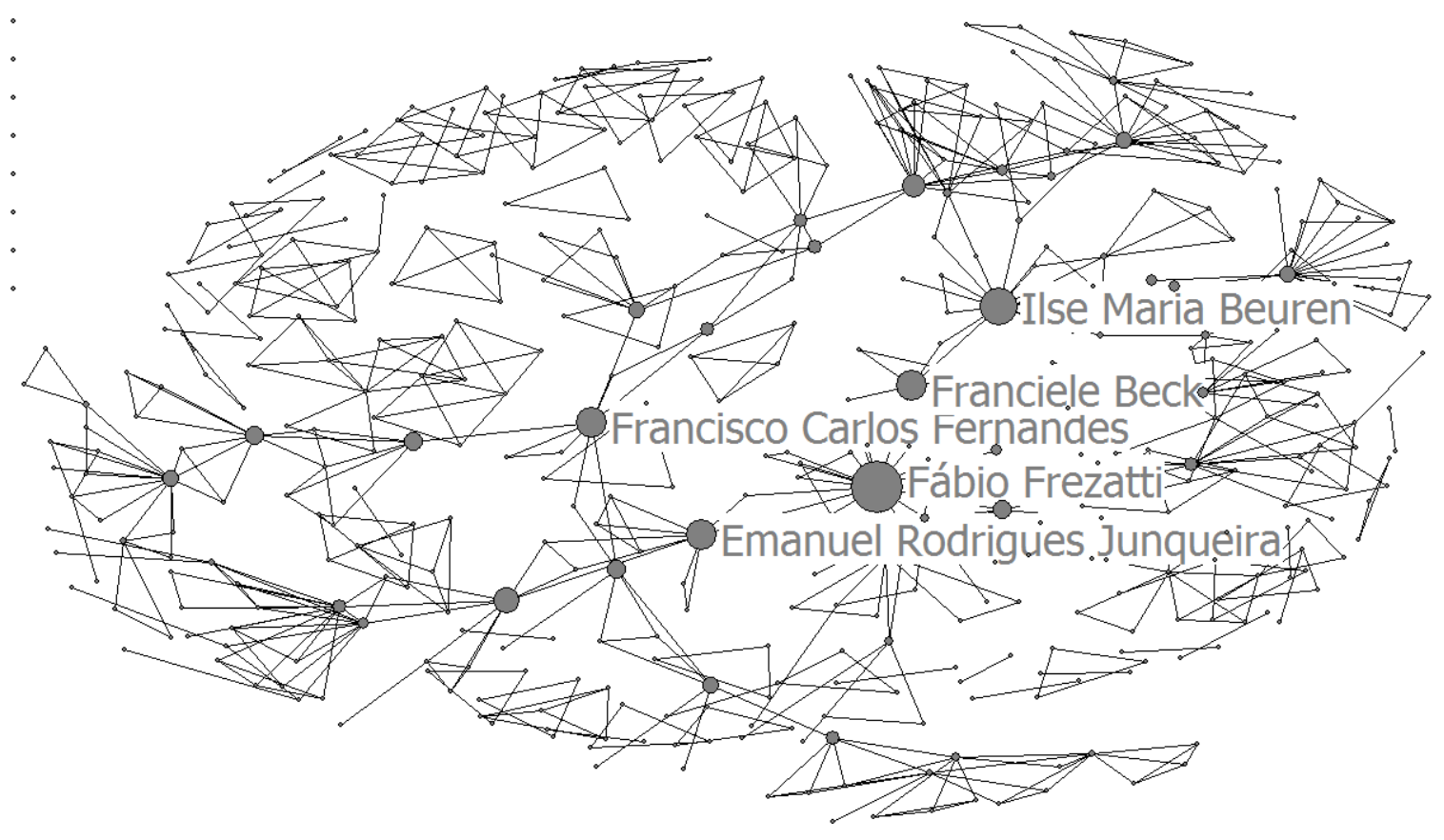

Fonte: Dados da pesquisa

Já a Figura 3 complementa a Figura 2, ao mostrar a mesma rede de coautoria desta investigação, contudo, enfatizando a centralidade de intermediação. Desta forma, enfatizam-se os acadêmicos: Fábio Frezatti, Ilse Maria Beuren, Franciele Beck, Emanuel R. Junqueira e Francisco Carlos Fernandes. Esboça-se que destes, somente os dois primeiros, ou seja, Fábio Frezatti e llse Maria Beuren ficam em evidência, além daqui, no tocante a produtividade dos autores e na rede de coautoria (degree). Tal achado demonstra a preponderância e a grandeza destes estudiosos para o aperfeiçoamento, fomento e socialização dos temas que norteiam a área temática objeto de estudo, influenciando com isso em seu desenvolvimento e difusão no contexto acadêmico literário nacional. As pesquisas de Costa (2010) e Ribeiro (2013) corroboram de maneira similar com os resultados contemplados neste estudo.

A Figura 4 contempla as 87 IESs identificadas nesta investigação, colocando em realce as 10 mais produtivas. 
Figura 4: IESs identificadas no estudo

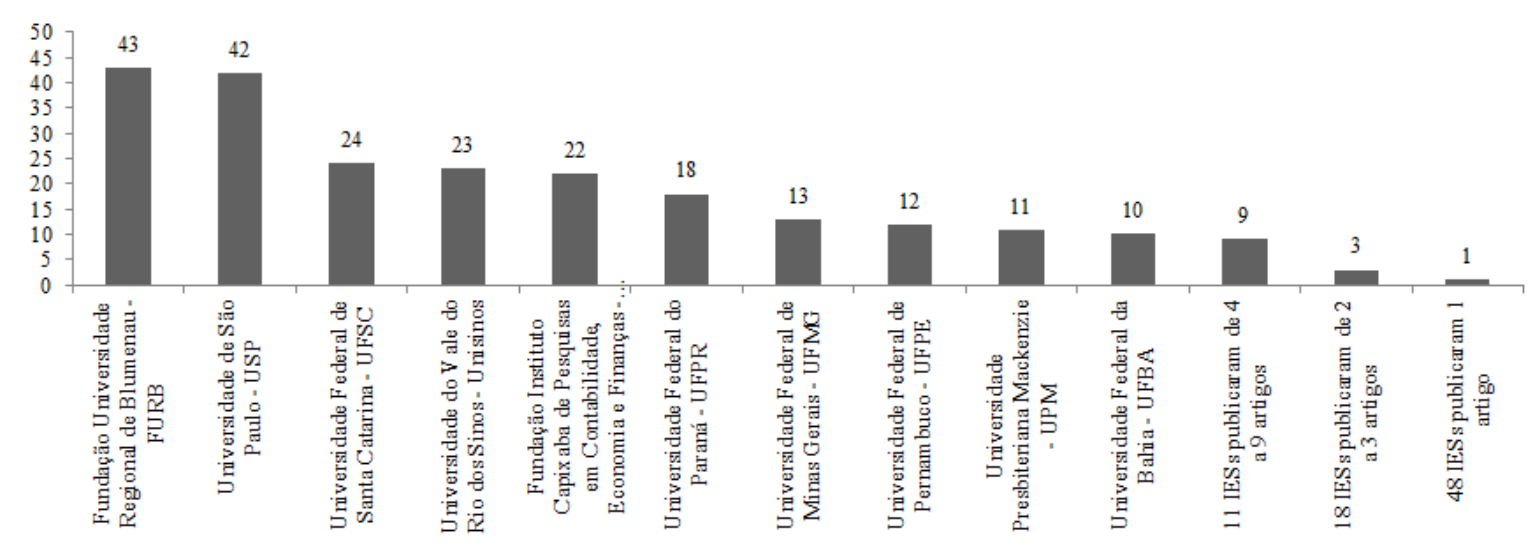

Fonte: Dados da pesquisa

A FURB foi a instituição com maior desempenho nas publicações neste estudo, com 43 artigos. Em seguida, surge a USP com 42 divulgações. Ribeiro (2013) em seu trabalho, também identificou a USP como a IES mais profícua no que tange a socialização da área temática Controladoria e Contabilidade Gerencial. Em terceiro lugar está a UFSC, com 24 artigos evidenciados. Em seguida surge a Unisinos com 23 estudos contemplados. Com 22 está a Fucape. Com 18 publicações tem-se a UFPR. A UFMG aparece em seguida com 13 papers. A UFPE está com 12 trabalhos difundidos. Com 11 surge a UPM. E com 10 aparece a UFBA.

De maneira geral, 10 IESs publicaram de 10 a 43 estudos. 29 instituições divulgaram de dois a nove artigos. E grande parte das IESs, ou seja, 48, evidenciaram apenas uma investigação cada. Ao observar os achados desta seção, constata-se a preocupação do congresso Anpcont em abrir as portas para várias IESs do Brasil e também do exterior, já que, seis instituições internacionais divulgaram seus trabalhos no referido congresso, foram elas: Universidade de Valencia (dois artigos), Universidade Regional Integrada do Alto Uruguai (um artigo), Universidade do Arizona (um artigo), Universidade de Essex (um artigo), Universidade de Lyon (um artigo) e a Universidade de Roehampton (um artigo).

Estas informações ajudam a entender como o referido congresso vem amadurecendo e de alguma forma se legitimando na academia, tornando-se assim um dos principais congressos da área contábil do Brasil (SCHMITZ et al., 2015). Os resultados desta seção ajudam a identificar, quais são as IESs mais relevantes, importantes, e, portanto, norteadoras do conhecimento da área temática Controladoria e Contabilidade Gerencial no Brasil. Tais achados são corroborados pelas Figuras 5 e 6 na sequência.

A Figura 5 visualiza a rede de colaboração das 87 IESs identificadas neste trabalho, porém, salientando a centralidade de grau. 
Figura 5: Rede social das IESs (centralidade de grau)
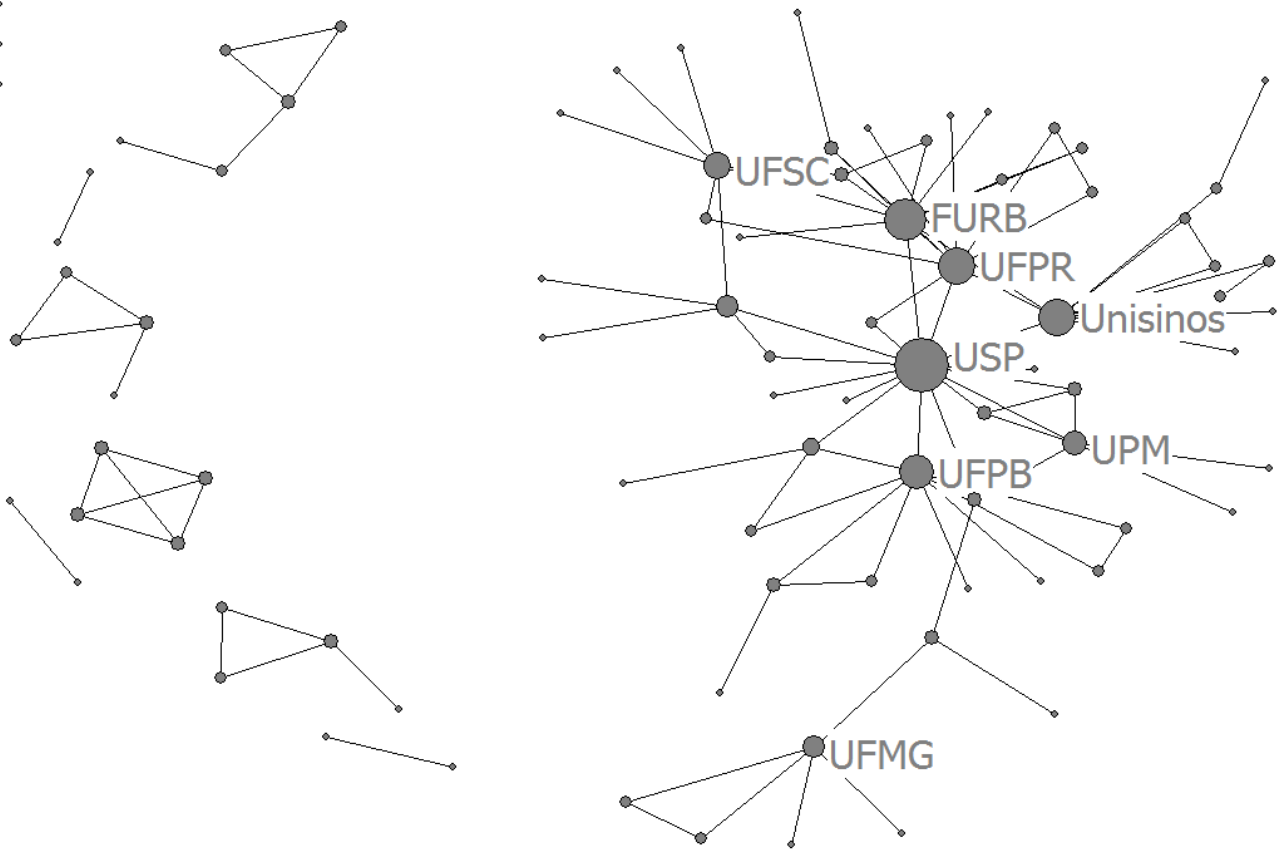

Fonte: Dados da pesquisa

A densidade da rede social das IESs é de 0,0366 , o que equivale a $3,66 \%$ das interações. Tal achado é superior em comparação a densidade de rede de coautoria, entretanto, ainda é baixo, visto que, ainda é possível interagir $96,34 \%$ a mais. É interessante notar, observando a Figura 5, que a maioria das conexões são visualizadas no lado direito das redes de colaboração das instituições. Esse mesmo nicho, encontram-se as IESs com maior centralidade de grau, ou seja, as que detém maior número de vínculos com outras instituições (CRUZ et al., 2011), são elas: USP, FURB, Unisinos, UFPR, UFPB, UFSC, UPM e UFMG. Dentre estas, nove compõem o grupo das 10 mais profícuas. O que de certa forma, é possível considerá-las como as mais relevantes e importantes na produção científica da área temática ora investigada, contribuindo em consequência para a difusão e socialização do conhecimento da referida área no panorama acadêmico nacional. 
Figura 6: Rede social das IESs (centralidade de intermediação)
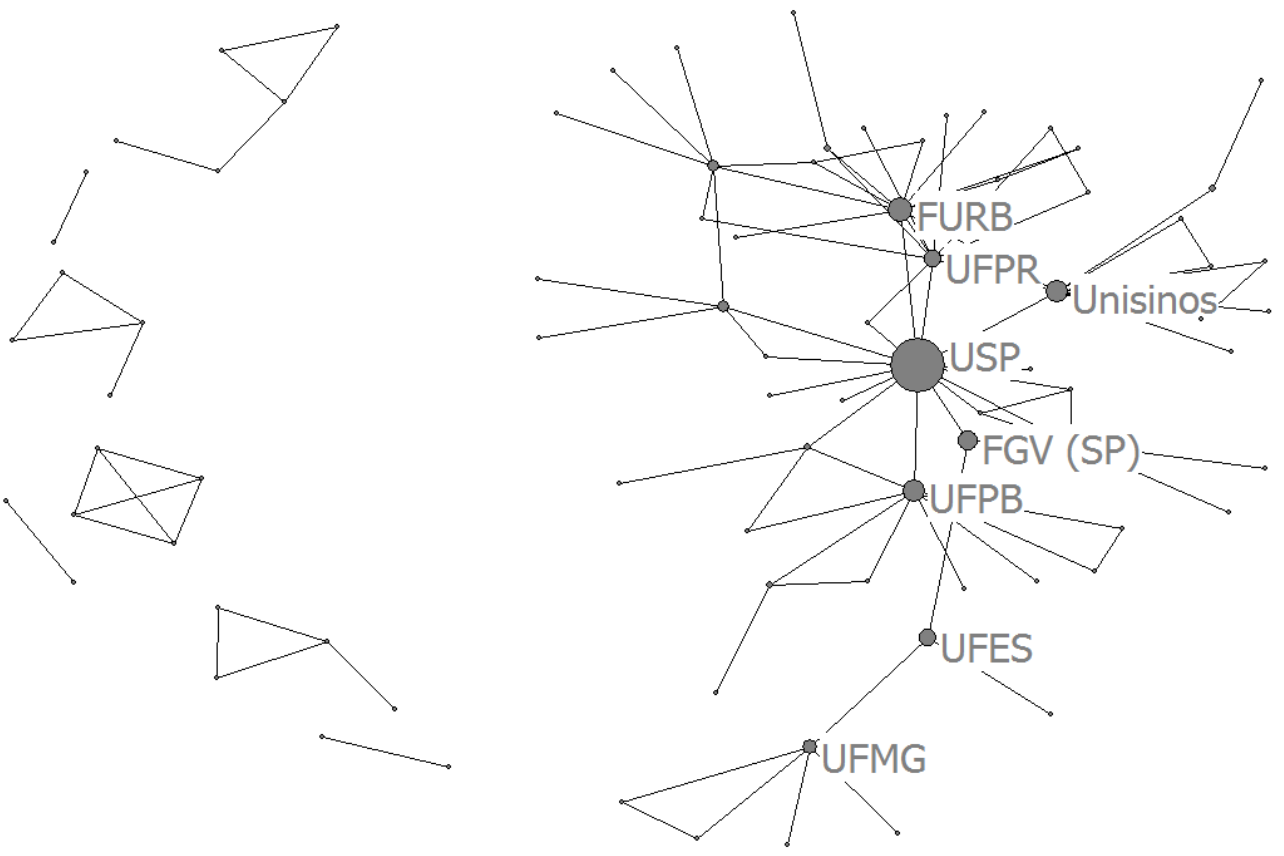

Fonte: Dados da pesquisa

Em relação a Figura 6, esta enfatiza a mesma rede social das instituições vista na Figura 5, contudo, colocando em foco a centralidade de intermediação. Sendo assim, as instituições realçadas nesta seção são: USP, FURB, Unisinos, UFPB, FGV (SP), UFPR, UFES e UFMG. Destas, cinco estão entre as demais mais produtivas, e seis estão entre as instituições com maior centralidade de grau. As IESs que se destacaram nas Figuras 4, 5 e 6 foram: FURB, USP, Unisinos, UFPR e UFMG.

Diante disso, é possível manifestar que estas instituições são as mais importantes, relevantes e preponderantes neste estudo, alcançando um grau de envergadura proeminente para o fomento, desenvolvimento e difusão do saber científico da área temática Controladoria e Contabilidade Gerencial, influenciando simultaneamente na evolução dos temas (Tabela 1) que se relacionam diretamente com as nuances e no bojo da citada área temática, contribuindo com isso na criação de valor científico na academia para as Ciências Contábeis.

A Tabela 1 mostra os 73 temas identificados e abordados neste trabalho, os quais relacionam-se diretamente com a área temática em investigação. Sendo que, para este estudo, serão discutidos os oito mais publicados. 
Tabela 1: Temas abordados

\begin{tabular}{|c|c|c|c|c|c|c|c|c|c|c|c|c|}
\hline Temas/Anos & 07 & 08 & 09 & 10 & 11 & 12 & 13 & 14 & 15 & 16 & Total & $\%$ \\
\hline Gestão de custos & 5 & 3 & & 5 & 2 & 2 & 3 & 1 & 9 & 4 & 34 & $13,82 \%$ \\
\hline Processo orçamentário & & 1 & & 3 & 3 & 2 & 7 & 5 & 2 & 1 & 24 & $9,76 \%$ \\
\hline Contabilidade gerencial & 2 & 2 & 3 & 3 & & 4 & 3 & 2 & 1 & 2 & 22 & $8,94 \%$ \\
\hline Controladoria & 1 & 2 & 3 & 1 & & 3 & 1 & & 1 & 1 & 13 & $5,28 \%$ \\
\hline Controle gerencial & 2 & & 1 & 2 & & 2 & 1 & & 2 & 3 & 13 & $5,28 \%$ \\
\hline Balanced Scorecard & 1 & 3 & & 1 & 1 & 1 & & 1 & 3 & & 11 & $4,47 \%$ \\
\hline Gestão pública & & & 1 & 2 & 3 & & 2 & 2 & 1 & & 11 & $4,47 \%$ \\
\hline Governança corporativa & & & 1 & & 1 & & & 3 & 1 & 2 & 8 & $3,25 \%$ \\
\hline Remuneração & & 1 & & & & 2 & 2 & & 1 & 1 & 7 & $2,85 \%$ \\
\hline Avaliação de desempenho & & & & & & & 2 & 1 & 2 & 1 & 6 & $2,44 \%$ \\
\hline Gestão de riscos & & & & & 1 & 1 & & 3 & & 1 & 6 & $2,44 \%$ \\
\hline Contabilidade internacional & & & 1 & & 1 & 1 & & 1 & & & 4 & $1,63 \%$ \\
\hline Desempenho financeiro & & & & 1 & 1 & & & & 1 & 1 & 4 & $1,63 \%$ \\
\hline Tecnologia da Informação & & & & & & 2 & & & 1 & 1 & 4 & $1,63 \%$ \\
\hline Ciclo de vida organizacional & 1 & & & & 1 & & 1 & & & & 3 & $1,22 \%$ \\
\hline Franchising & & & & & & & & & & 3 & 3 & $1,22 \%$ \\
\hline Modelos de gestão & & 1 & 1 & & 1 & & & & & & 3 & $1,22 \%$ \\
\hline Processo decisório & & & & 1 & 1 & & & & & 1 & 3 & $1,22 \%$ \\
\hline Tomada de decisão & 1 & & 1 & & 1 & & & & & & 3 & $1,22 \%$ \\
\hline Capital intelectual & & 1 & & & 1 & & & & & & 2 & $0,81 \%$ \\
\hline Controle interno & & & & & & & & 2 & & & 2 & $0,81 \%$ \\
\hline Fraudes contábeis & & & & & 1 & 1 & & & & & 2 & $0,81 \%$ \\
\hline Gestão ambiental & & & 1 & & & & 1 & & & & 2 & $0,81 \%$ \\
\hline Informação contábil & & & 1 & & 1 & & & & & & 2 & $0,81 \%$ \\
\hline Lei de Responsabilidade Fiscal (LRF) & 1 & & & & 1 & & & & & & 2 & $0,81 \%$ \\
\hline Logística & & & & 1 & & & & 1 & & & 2 & $0,81 \%$ \\
\hline Preço de transferência & 1 & & & & 1 & & & & & & 2 & $0,81 \%$ \\
\hline Resource-Based View (RBV) & & & 2 & & & & & & & & 2 & $0,81 \%$ \\
\hline Sistema de Informação Gerencial (SIG) & & 1 & & & & & & & & 1 & 2 & $0,81 \%$ \\
\hline
\end{tabular}

44 temas foram publicados 1 vez só

Fonte: Dados da pesquisa

O tema Gestão de custos foi o mais publicado com 34 artigos. Em vista disso, os estudiosos Costa (2010) e Ribeiro (2013) confirmam tal achado em seus respectivos trabalhos. O destaque ao tema gestão de custos é em decorrência de este ser basilar nas tomadas de decisões, no controle gerencial (BITTI; AQUINO; CARDOSO, 2011) e no processo orçamentário (BEUREN; WIENHAGE, 2013).

Ressalta-se também que o Custeio Baseado em Atividades ( $A B C$ ), isto é, o custeio $A B C$, foi o mais trabalhado nos estudos sobre gestão de custos, aparecendo quatro vezes. Salienta que o objetivo do método de custeio $A B C$ é rastrear as atividades mais importantes da organização, identificando nortes de consumo dos recursos e, por meio dessa análise, planejar o uso eficiente e eficaz dos recursos utilizados pela organização, fomentando seus resultados (WERNKE, 2005). 
Em seguida aparece o tema Processo orçamentário, que é considerado uma etapa essencial no planejamento de uma organização (HEINZMANN; LAVARDA, 2011), com 24 estudos divulgados. Sendo que o assunto Folga orçamentária foi o mais discutido nas pesquisas sobre processo orçamentário. Realça-se que a folga orçamentária tem se destacado como foco de investigação, podendo ser pelo fato de seu impacto no desempenho das organizações (BEUREN; WIENHAGE, 2013). O estudo de Blonkoski, Antonelli e Bortoluzzi (2017) corroboram de maneira análoga com este achado.

As temáticas Contabilidade gerencial e Controladoria, surgem em seguida com 22 e 13 publicações nos artigos que as colocaram como foco principal. Versa-se que o referido estudo faz justamente a análise da produção científica da área temática Controladoria e Contabilidade Gerencial, e de certa forma, o destaque para estes temas já era esperado, sendo que suas respectivas importâncias, no controle gerencial (FRANCISCHETTI; POKER JUNIOR; PADOVEZE, 2017), e no desempenho empresarial (NASCIMENTO; GALLON, 2008; COSTA, 2010; SANTOS; ROCHA, 2011), e suas analogias (MARTIN, 2002; BOFF; BEUREN; GUERREIRO, 2008; LUNKES et al., 2012; LUNKES et al., 2014) já foram descritas e discutidas na fundamentação teórica deste estudo.

O assunto Controle gerencial vem a seguir com 13 publicações. Sua relação com os temas controladoria e contabilidade gerencial é intrínseca. Explica-se, pois, a área de controladoria atua no controle gerencial (FRANCISCHETTI; POKER JUNIOR; PADOVEZE, 2017), e que os artefatos de contabilidade gerencial (REIS; TEIXEIRA, 2013), compõem um conjunto de rotinas de controle gerencial (ALMEIDA; STARKE JUNIOR; FREITAG, 2011). Com isso, tanto a controladoria, como também a contabilidade gerencial, exerce influência no controle gerencial das organizações (LUNKES et al., 2014), impactando em seu processo de gestão (FRANCISCHETTI; POKER JUNIOR; PADOVEZE, 2017).

Os temas, Balanced Scorecard (BSc) e Gestão pública, foram divulgados ambos 11 vezes. O BSc está intrinsicamente ligado a controladoria (LUNKES et al., 2009) e a contabilidade gerencial (KRAEMER, 2009; COOPER; EZZAMEL; QU, 2017). O motivo disto é porque o BSc é importante para o processo orçamentário (FREZATTI, 2005; NGUYEN; WEIGEL; HIEBL, 2018), sendo assim considerado relevante ferramenta de controle, aferição, acompanhamento e comunicação das estratégias da organização (SOUZA et al., 2016). É importante ressaltar que a estrutura basilar do BSc é constituída pelo conjunto de objetivos, indicadores de desempenho, metas e iniciativas de uma organização abrangendo quatro perspectivas: financeira, cliente, processo interno e aprendizado e crescimento (GAVA NETO et al., 2015).

Já a Governança Corporativa foi publicada em oito artigos como tema principal. Este destaque da governança corporativa como tema publicado nestes oito artigos divulgados na área temática Controladoria e Contabilidade Gerencial (VAN DER POLL; MTHIYANE, 2018), é em virtude de a controladoria ser vista como um mecanismo interno de governança corporativa (NASCIMENTO; BIANCHI; TERRA, 2007). Diante do panorama, entende-se que a governança corporativa é alicerçada pelos princípios: disclosure, accountability, fairness e compliance (RIBEIRO, 2014), se relacionando assim, com o conceito relativo sobre o modo de como as organizações devem ser gerenciadas e controladas (MARQUES, 2007). 


\section{CONSIDERAÇÕES FINAIS}

O objetivo deste estudo foi analisar a produção científica da área temática Controladoria e Contabilidade Gerencial divulgada no congresso Anpcont de 2007 a 2016. Para isso, utilizou-se a bibliometria que é uma técnica quantitativa usada para calcular a difusão do conhecimento científico e o fluxo da informação, sob diversos prismas (PERUCCHI; ARAÚJO JÚNIOR, 2012). E, por meio da rede social é possível observar características, como: padrões de colaboração entre os atores de uma rede; conectividade entre estes atores; formação de clusters; e o fluxo de comunicação, informação e conhecimento dentro da rede social (BORDIN; GONÇALVES; TODESCO, 2014).

De maneira geral este trabalho alcançou os resultados almejados, visto que, a questão de pesquisa foi respondida e o objetivo foi alcançado. A informação agregada aqui denota um conhecimento relevante sobre a área temática Controladoria e Contabilidade Gerencial durante os 10 anos que ela foi divulgada no congresso Anpcont. Foi mostrado os autores mais importantes e com maior envergadura no trato e na publicação de temas conexos a mencionada área temática, ajudando com isso, em um amplo saber contemporâneo, contribuindo para vislumbrar como o conhecimento científico desta área foi abrangida, disseminada e socializada em uma década.

As redes dos atores foram visualizadas, contemplando assim suas colaborações e interações (MELLO; CRUBELLATE; ROSSONI, 2010), proporcionando melhor entender e compreender como estas conexões ajudam no desenvolvimento e difusão da comunicação, informação e conhecimento científico da área investigada (KIMURA; BASSO; MARTIN, 2008). O que se faz notar um domínio de poucos autores e IESs na produção científica e na difusão do saber acadêmico na área Controladoria e Contabilidade Gerencial, fazendo-os os mais imponentes e preponderantes no contexto científico literário nacional da área.

Poder saber quais temas foram mais abordados é uma oportunidade para manifestar como os autores e suas respectivas instituições promovem o saber, agregando valor científico não somente para a área temática objetivo de estudo, mas também, e sobretudo para o campo maior do saber que agrega a mencionada área que são as Ciências Contábeis. Uma diversidade rica de temas, sejam eles legitimados, maduros, emergentes e/ou embrionários, propícia um engrandecimento e robustez do conhecimento científico da Controladoria e da Contabilidade Gerencial, contribuindo, consequentemente para seu maior desenvolvimento e alargamento na academia.

É importante salientar que, os temas poucos abordados neste estudo, é uma oportunidade grande de surgimento de novos trabalhos científicos, visto que, estes, ao serem mais estudados e posteriormente divulgados, não somente no congresso objeto de pesquisa, mas também em outros similares e, em revistas científicas (DUMAY et al., 2018), contribui para uma evolução e crescimento da área Controladoria e Contabilidade Gerencial em conjunto, como também, de maneira individual, impactando, com isso, no enriquecimento das Ciências Contábeis no Brasil.

Em suma, a referida pesquisa analisou a produção científica da área temática Controladoria e Contabilidade Gerencial divulgada no congresso Anpcont de 2007 a 2016. Com isso, este artigo contribui de maneira robusta e alargada para o melhor entendimento e compreensão da área do conhecimento analisada mediante o mapeamento das variáveis bibliométricas e sociométricas enfocadas neste trabalho. Em suma, entende-se e compreende-se que a área do saber aqui analisada traz novas contribuições, perspectivas e 
tendências para debate acadêmico das Ciências Contábeis do Brasil à luz do congresso Anpcont, possibilitando surgir agendas de pesquisa para a citada área, criando valor acadêmico e proporcionando surgir novos debates, propiciando com isso o surgimento de novos congressos e, a posteriori, a criação de novos periódicos científicos nacionais.

Como limitação, este estudo focou apenas em analisar a produção científica da área temática Controladoria e Contabilidade Gerencial no congresso Anpcont. Explica-se e justifica-se isso em virtude dos 10 anos de pesquisa e de divulgação de publicações deste evento no âmbito nacional. Contudo, reitera-se a importância de idealizar novos estudos, sejam similares ou não a este. E, em decorrência disso, sugere-se para estudos futuros uma investigação que analisasse comparativamente, dois ou três congressos científicos das Ciências Contábeis no Brasil, sobre a área recém analisada, esses congressos poderiam ser o Anpcont, junto com o da USP e o da UFSC, por exemplo. Outra sugestão é focar em congressos no panorama internacional, e entender como a controladoria e a contabilidade gerencial são publicadas, disseminadas e socializadas no exterior. Com isso, pode-se em estudos posteriores, fazer uma análise comparativa entre os artigos publicados em âmbito nacional destes congressos, com as pesquisas divulgadas no contexto internacional de congressos da área. Outra sugestão é, trabalhar mais indicadores bibliométricos e de rede social, para ter mais dados e, posteriormente, mais informações. E, por fim, uma sugestão interessante seria explorar o impacto da pesquisa em contabilidade gerencial por meio de uma revisão teórica (GATTI, 2018), no âmbito nacional, sob a ótica dos artigos publicados em congressos e, em especial de estudos divulgados em periódicos de alto fator de impacto do Brasil.

\section{REFERÊNCIAS}

ALBUQUERQUE, L. S. et al. Análise bibliométrica dos artigos sobre controladoria publicados no congresso USP de controladoria e contabilidade no período de 2004 a 2010. Revista Evidenciação Contábil \& Finanças, João Pessoa, v. 1, n. 2, p. 123-138, jul./dez. 2013.

ALMEIDA, L. B. de; STARKE JUNIOR, P. C.; FREITAG, V. C. Um ensaio sobre as forças que modelam a dinâmica da contabilidade gerencial em empresas prestadoras de serviços. Revista de Educação e Pesquisa em Contabilidade, Brasília, v. 5, n. 3, p. 117-140, set./dez. 2011.

AMARAL, M. R. do. et al. Perfil dos autores na produção científica em mercado financeiro de crédito e de capitais nos congressos USP de controladoria e contabilidade e congresso Anpcont. Revista Evidenciação Contábil \& Finanças, João Pessoa, v. 2, n. 2, p. 55-68, mai./ago. 2014.

ANPCONT - Associação Nacional de Programas de Pós-Graduação em Ciências Contábeis. Áreas temáticas. Disponível em: < http://www.anpcont.org.br/congressos-anpcont>. Acesso em: 20 fev.2017.

ARAÚJO, E. A. T.; SILVA, W. A. C. Pesquisa científica em contabilidade gerencial nos enanpads de 2003 a 2008. Revista Universo Contábil, Blumenau, v. 6, n. 3, p. 29-44, jul./set. 2010.

ARBOIT, A. E.; BUFREM, L. S. (2011). Produção de trabalhos científicos em eventos nacionais da área de ciência da informação. TransInformação, Campinas, v. 23, n. 3, p. 207-217, set./dez. 2011.

BEUREN, I.; MACOHON, E. Institucionalização de hábitos e rotinas na contabilidade gerencial à luz da teoria da contingência: Um estudo em indústrias de móveis em São Bento do Sul. Revista Portuguesa e Brasileira de Gestão, Lisboa, v. 10, n. 1-2, p. 78-91, jan. 2011.

BEUREN, I. M.; SCHLINDWEIN, A. C.; PASQUAL, D. L. Abordagem da controladoria em trabalhos publicados no Enanpad e no congresso USP de controladoria e contabilidade de 2001 a 2006. Revista Contabilidade \& Finanças, São Paulo, v. 18, n. 45, p. 22-37, set./dez. 2007.

BEUREN, I. M.; WIENHAGE, P. Folga organizacional no processo de gestão do orçamento: um estudo no Senac de Santa Catarina. Revista Eletrônica de Administração, Porto Alegre, v. 75, n. 2, p. 274-300, mai./ago. 2013.

BITTI, E. J. S.; AQUINO, A. C. B. de; CARDOSO, R. L. Adoção de sistemas de custos no setor público: reflexões sobre a literatura nacional veiculada em periódicos acadêmicos. Revista Universo Contábil, Blumenau, v. 7, n. 3, p. 06-24, jul./set. 2011. 
BLONKOSKI, P. R.; ANTONELLI, R. A.; BORTOLUZZI, S. C. Contabilidade gerencial: análise bibliométrica e sistêmica da literatura científica internacional. Pretexto, v. 18, n. 1, p. 80-99, 2017.

BOFF, M. C.; BEUREN, I. M.; GUERREIRO, R. Institucionalização de hábitos e rotinas da controladoria em empresas do estado de Santa Catarina. Organizações \& Sociedade, Salvador, v. 15, n. 46, jul./set. 2008.

BORDIN, A. S.; GONÇALVES, A. L.; TODESCO, J. L. Análise da colaboração científica departamental através de redes de coautoria. Perspectivas em Ciência da Informação, Belo Horizonte, v. 19, n. 2, p. 37-52, abr./jun. 2014.

BRIZOLLA, M. M. B.; CHIARELLO, T. C.; LAVARDA, C. E. F. Abordagem a respeito da controladoria e contabilidade gerencial: um estudo das redes sociais publicado em periódicos internacionais. Revista de Gestão e Contabilidade da UFPI, Floriano, v. 1, n. 1, p. 119-140, jan./jun. 2014.

BUI, B.; DE VILLIERS, C. Business strategies and management accounting in response to climate change risk exposure and regulatory uncertainty. The British Accounting Review, v. 49, n. 1, p. 4-24, 2017.

CABRAL, I.; SIQUEIRA, J. R. M. de; BATISTA, R. S. O diálogo das ciências contábeis com as ciências humanas e demais ciências sociais: uma análise da produção acadêmica do congresso USP de controladoria e contabilidade e Enanpad (2004-2007). Revista de Educação e Pesquisa em Contabilidade, Brasília, v. 5, Edição Especial, p. 100-125, set./dez. 2011.

CARNEGIE, G. D.; NAPIER, C. J. The Accounting, Auditing \& Accountability Journal Community in its 30th year. Accounting, Auditing \& Accountability Journal, v. 30, n. 8, p. 1642-1676, 2017.

CAVALCANTE, D. S. et al. Características da controladoria nas maiores companhias listadas na BM\&FBovespa. Revista Universo Contábil, Blumenau, v. 8, n. 3, p. 113-134, jul./set. 2012.

CHAKRABORTY, V.; CHIU, V.; VASARHELYI, M. Automatic classification of accounting literature. International Journal of Accounting Information Systems, v. 15, 122-148, 2014.

COOPER, D. J.; EZZAMEL, M.; QU, S. Q. Popularizing a management accounting idea: The case of the balanced scorecard. Contemporary Accounting Research, v. 34, n. 2, p. 991-1025, 2017.

CORREA, R. O.; TEIXEIRA, R. M. Redes sociais empreendedoras para obtenção de recursos e legitimação organizacional: estudo de casos múltiplos com empreendedores sociais. Revista de Administração Mackenzie, São Paulo, v. 16 , n. 1, p. 62-95, jan./feb. 2015.

CORREIA, A. E. G. C.; ALVARENGA, L.; GRACIA, J. C. R. Produção científica: reflexos da avaliação nos programas de pós-graduação em Física. Em Questão, Porto Alegre, v. 18, Edição Especial, p. 231-247, dez. 2012.

COSENZA, J. P. et al. Análise das características e similaridades presentes na produção científica dos congressos ANPCONT 2007-2014. Revista Contemporânea de Contabilidade, Florianópolis, v. 13, n. 28, p. 19-56,

jan./abr. 2016.

COSTA, F. A produção do saber nos campos de controladoria e contabilidade gerencial: uma análise da produção científica inspirada na arqueologia foucaultiana. Dissertação (Mestrado em Contabilidade), UFPR, Paraná, 2010,160 pg.

COSTA, T. et al. A bibliometria e a avaliação da produção científica: indicadores e ferramentas. In: CONGRESSO NACIONAL DE BIBLIOTECÁRIOS, ARQUIVISTAS E DOCUMENTALISTAS, n. 11, Lisboa, Anais eletrônicos..., 2012. Disponível em: < http://www.bad.pt/publicacoes/index.php/congressosbad/article/view/429>Acesso em: 25 fev. 2017.

CRUZ, A. P. C. da. et al. Perfil das redes de cooperação científica: congresso USP de controladoria e contabilidade - 2001 a 2009. Revista Contabilidade \& Finanças, São Paulo, v. 22, n. 55, p. 64-87, jan./fev./mar./abr. 2011.

CUNHA, P. R. da; DAL MAGRO, C. B.; DIAS, D. R. Análise do problema de pesquisa dos artigos científicos publicados no $11^{\circ}$ congresso USP de controladoria e contabilidade. Revista de Contabilidade e Organizações, Ribeirão Preto, v. 6 , n. 15, p. 124-141, mai./ago. 2012.

CUNHA, P. R. da; CORREA, D. C.; BEUREN, I. M. Assuntos de auditoria publicados nos periódicos nacionais e internacionais de contabilidade listados no qualis Capes. Revista de Informação Contábil, Recife, v. 4, n. 1, p. 57-75, jan./mar. 2010.

DE LUCA, M. M. M. et al. Participação feminina na produção científica em contabilidade publicada nos anais dos eventos Enanpad, Congresso USP de Controladoria e Contabilidade e Congresso Anpcont. Revista de Contabilidade e Organizações, Ribeirão Preto, v. 5, n. 11, p. 146-164, jan./abr. 2011.

DUMAY, J.; DE VILLIERS, C.; GUTHRIE, J.; HSIAO, P. C. Thirty years of Accounting, Auditing and Accountability Journal: A critical study of the journal's most cited articles. Accounting, Auditing \& Accountability Journal, v. 31, n. 5, p. 1510-1541, 2018.

FRANCISCHETTI, C. E.; POKER JUNIOR, J. H.; PADOVEZE, C. L. Contabilometria: análise bibliométrica, tendências e reflexões em publicações da base de dados scopus de 1982 até 2014. Brazilian Journal of Quantitative Methods Applied to Accounting, Monte Carmelo, v. 4, n. 1, p. 31-44, jan./jun. 2017. 
FREZATTI, F. Beyond budgeting: inovação ou resgate de antigos conceitos do orçamento empresarial? Revista de Administração de Empresas, São Paulo, v. 45, n. 2, p. 23-33, abr./jun. 2005.

FREZATTI, F. et al. Análise do relacionamento entre a contabilidade gerencial e o processo de planejamento das organizaçőes brasileiras. Revista de Administração Contemporânea, Curitiba, v. 11, n. SPE2, p. 33-54, 2007.

GATTI, M. The impact of management accounting research: an analysis of the past and a look at the future. International Journal of Business and Management, v. 13, n. 5, p. 47-60, 2018.

GAVA NETO, J. et al. Estratégia, competências e desempenho em empresas de software: evidencias de um levantamento no estado do Paraná. Revista de Administração da UNIMEP, Piracicaba, v. 13, n. 3, p. 154-183, set./dez. 2015.

GUERREIRO, R. Editorial: a abordagem institucional na contabilidade gerencial. Revista Contabilidade \& Finanças, São Paulo, v. 17, n. 40, p. 1-3, jan./apr. 2006.

GUERREIRO, R.; FREZATTI, F.; CASADO, T. Em busca de um melhor entendimento da contabilidade gerencial através da integração de conceitos da psicologia, cultura organizacional e teoria institucional. Revista Contabilidade \& Finanças, São Paulo, v. 17, n. spe, p. 7-21, set. 2006

GUERREIRO, R. et al. O entendimento da contabilidade gerencial sob a ótica da teoria institucional. Organizações \& Sociedade, Salvador, v. 12, n. 35, p. 91-106, out./dez. 2005.

GUERREIRO, R.; PEREIRA, C. A.; REZENDE, A. J. Em busca do entendimento da formação dos hábitos e das rotinas da contabilidade gerencial: um estudo de caso. Revista de Administração Mackenzie, São Paulo, v. 7, n. 2, p. 78-101, 2008.

GUFFEY, D. M.; HARP, N. L. The journal of management accounting research: A content and citation analysis of the first 25 years. Journal of Management Accounting Research, v. 29, n. 3, p. 93-110, 2016.

HEINZMANN, L. M.; LAVARDA, C. E. F. Cultura organizacional e o processo de planejamento e controle orçamentário. Revista de Contabilidade e Organizações, Ribeirão Preto, v. 5, n. 13, p. 5-19, set./dez. 2011.

KIMURA, H.; BASSO, L. F. C.; MARTIN, D. M. L. Redes sociais e o marketing de inovações. Revista de Administração Mackenzie, São Paulo, v. 9, n. 1, p. 157-181, 2008.

KRAEMER, M. E. P. O balanced scorecard e seu impacto na contabilidade gerencial. Revista Contabilidade Vista e Revista, Belo Horizonte, v. 13, n. 3, p. 53-70, 2009.

LAUDELINO, J. A. de S.; NAVARRO, R. M.; BEUREN, I. M. Análise da abordagem da controladoria nas dissertações e teses dos programas acadêmicos de mestrado e doutorado em ciências contábeis no Brasil. Revista de Contabilidade da UFBA, Salvador, v. 4, n. 2, p. 21-33, mai./ago. 2010.

LOHMANN, C.; EULERICH, M. Publication trends and the network of publishing institutions in accounting: data on The Accounting Review, 1926-2014. Accounting History Review, v. 27, n. 1, p. 1-25, 2017.

LUCIANI, J. C. J.; CARDOSO, N. J.; BEUREN, I. M. Inserção da controladoria em artigos de periódicos nacionais classificados no Sistema Qualis da Capes. Revista Contabilidade Vista e Revista, Belo Horizonte, v. 18, n. 1, p. 11-26, jan./mar. 2007.

LUNKES, R. J.; FELIU, V. M. R.; ROSA, F. S. da. Pesquisa científica em contabilidade gerencial: estudo comparativo entre Espanha e Brasil. Contaduría y Administración, México, v. 57, n. 2, p. 159-184, abr./jun. 2012.

LUNKES, R. J. et al. Estudo descritivo sobre o desenvolvimento da contabilidade gerencial no brasil sob a perspectiva da legitimidade. Advances in Scientific and Applied Accounting, São Paulo, v. 7, n. 1, p. 97-121, jan./abr. 2014.

LUNKES, R. J.; GASPARETTO, V.; SCHNORRENBERGER, D. Um estudo sobre as funções da controladoria. Revista de Contabilidade e Organizações, Ribeirão Preto, v. 4, n. 10, p. 106-126, set./dez. 2010.

LUNKES, R. J. et al. Considerações sobre as funções da controladoria nos Estados Unidos, Alemanha e Brasil. Revista Universo Contábil, Blumenau, v. 5, n.4, p. 63-75, out./dez., 2009.

LUNKES, R. J. et al. Análise da legitimidade sociopolítica e cognitiva da controladoria no Brasil. Revista Contabilidade \& Finanças, São Paulo, v. 23, n. 59, p. 89-101, maio/jun./jul./ago. 2012.

MARQUES, M. da C. da C. Aplicação dos princípios da governança corporativa ao sector público. Revista de Administração Contemporânea, Curitiba, v. 11, n. 2, p. 11-26, abr./jun. 2007.

MARTIN, N. C. Da Contabilidade à controladoria: a evolução necessária. Revista Contabilidade \& Finanças, São Paulo, n. 28, p. 7-28, jan./abr. 2002.

MELLO, C. M. de; CRUBELLATE, J. M.; ROSSONI, L. Dinâmica de relacionamento e prováveis respostas estratégicas de programas brasileiros de pós-graduação em administração à avaliação da Capes: proposições institucionais a partir da análise de redes de co-autorias. Revista de Administração Contemporânea, Curitiba, v. 14, n. 3, p. 434-457, mai./jun. 2010.

MELO-SILVA, G. Redes de investimento e o financiamento de campanhas em Minas Gerais. Revista de Administração Pública, Rio de Janeiro, v. 50, n. 4, p. 689-709, jul./ago. 2016; 
MIRANDA, G. J. et al. A pesquisa em educação contábil: produção científica e preferências de doutores no período de 2005 a 2009. Revista Contabilidade \& Finanças, São Paulo, v. 24, n. 61, p. 75-88, jan./fev./mar./abr. 2013.

MURCIA, F. C. de S.; ROSA, C. A.; BORBA, J. A. Produção Científica em Ciências Contábeis: uma comparação entre a meta estabelecida pela CAPES e a publicação de artigos por parte dos docentes de Programas de Pós-Graduação. Contabilidade, Gestão e Governança, Brasília, v. 16, n. 1, p. 68-81, jan./abr. 2013.

MENDES-DA-SILVA, W.; ONUSIC, L. M.; GIGLIO, E. M. Rede de Pesquisadores de Finanças no Brasil: Um Mundo Pequeno Feito por Poucos. Revista de Administração Contemporânea, Rio de Janeiro, v. 17, n. 6, p. 739-763, nov./dez. 2013.

NASCIMENTO, A. M.; BIANCHI, M.; TERRA, P. R. S. A controladoria como um mecanismo interno de governança corporativa: evidências de uma survey comparativa entre empresas de capital brasileiro e norte-americano. ABCustos Associação Brasileira de Custos, v. 2, n. 2, mai./ago. 2007.

NASCIMENTO, A. R. do; JUNQUEIRA, E.; MARTINS, G. de A. Pesquisa acadêmica em contabilidade gerencial no Brasil: análise e reflexões sobre teorias, metodologias e paradigmas. Revista de Administração Contemporânea, Curitiba, v. 14, n. 6, p. 1113-1133, nov./dez. 2010.

NASCIMENTO, C. do; GALLON, A. V. A contabilidade como base informacional ao desenvolvimento da atividade aqüicola: um estudo multicaso. Gestão \& Regionalidade, São Caetano do Sul, v. 24, n. 69, jan./abr. 2008.

NASCIMENTO, S. do; PEREIRA, A. M.; TOLEDO FILHO, J. R. de. Produção científica em periódicos de contabilidade relacionada ao mercado de capitais 2010. Contabilidade, Gestão e Governança, Brasília, v. 13, n. 1, p. 32-43, jan./abr. 2010;

NECYK, G. A.; FREZATTI, F. A contabilidade gerencial: uma perspectiva de ciclo de vida de seu desenvolvimento nas organizações. Organizações \& Sociedade, Salvador, v. 17, n. 55, p. 725-744, out./dez. 2010.

NGUYEN, D. H.; WEIGEL, C.; HIEBL, M. R. W. Beyond budgeting: review and research agenda. Journal of Accounting \& Organizational Change, v. 14, n. 3, p. 314-337, 2018.

OLIVEIRA, E. K. F. de; BOENTE, D. R. Análise bibliométrica da produção científica recente sobre contabilidade gerencial. Organizações em Contexto, São Bernardo do Campo, v. 8, n. 15, jan./jun. 2012.

PADOVEZE, C. L. O papel da contabilidade gerencial no processo empresarial de criação de valor. Caderno de Estudos, São Paulo, n. 21, p. 01-16, mai./ago. 1999.

PELEIAS, I. R. et al. Dez anos de pesquisa científica em controladoria no brasil (1997 - 2006). Revista de Administração e Inovação, São Paulo, v. 7, n. 1, p. 193-217, jan./mar. 2010.

PÉRISSÉ, A. R. S.; NERY, J. A. da C. The relevance of social network analysis on the epidemiology and prevention of sexually transmitted diseases. Cadernos de Saúde Pública, Rio de Janeiro, v. 23, n. 3, p. 361-369, jan. 2007

PERUCCHI, V.; ARAÚJO JÚNIOR, R. H. de. Produção científica sobre inteligência competitiva da Faculdade de Ciência da Informação da Universidade de Brasília. Perspectivas em Ciência da Informação, Belo Horizonte, v. 17, n. 2, p. 37-56, abr./jun. 2012.

QUONIAM, L. et al. Inteligência obtida pela aplicação de data mining em base de teses francesas sobre o Brasil. Ciência da informação, Brasília, v. 30, n. 2, p. 20-28, mai./ago. 2001.

REIS, A. M. dos; TEIXEIRA, A. J. C. Utilização de artefatos de contabilidade gerencial nas sociedades cooperativas agropecuárias de Minas Gerais e sua relação com porte e desempenho financeiro. Revista de Educação e Pesquisa em Contabilidade, Brasília, v. 7, n. 4, p. 355-371, out./dez. 2013.

RIBEIRO, H. C. M. Contribuição do congresso USP ao estudo da área temática controladoria e contabilidade gerencial: uma bibliometria. Revista de Administração, Contabilidade e Economia, Joaçaba, v. 12, n. 2, p. 709-746, jul./dez. 2013.

RIBEIRO, H. C. M. Corporate governance versus corporate governance: an international review: uma análise comparativa da produção acadêmica do tema governança corporativa. Revista Contemporânea de Contabilidade, Florianópolis, v. 11, n. 23, p. 95-116, mai./ago. 2014.

RIBEIRO, R. R. M.; ESPEJO, M. M. dos S. B. Evolução das pesquisas em contabilidade gerencial: uma análise das opções temáticas em teses e dissertações no Brasil. Enfoque: Reflexão Contábil, Maringá, v. 32, n. 1, p. 49-63, jan./abr. 2013.

SANTOS, R. P. dos; ROCHA, W. Contabilidade focada nos concorrentes: um estudo exploratório no setor de agronegócios. Sociedade, Contabilidade e Gestão, Rio de Janeiro, v. 6, n. 1, jan./jun. 2011.

SARTORATTO, R.; LUNKES, R. J.; ROSA, F. S. da. A percepção dos estudantes de ciências contábeis sobre seus conhecimentos em controladoria. Revista de Contabilidade e Controladoria, Curitiba, v. 8, n. 1, p. 102-115, jan./abr. 2016.

SCHALTEGGER, S.; GIBASSIER, D.; ZVEZDOV, D. Is environmental management accounting a discipline? A bibliometric literature review. Meditari Accountancy Research, v. 21, n. 1, p. 4-31, 2013. 
SCHMITZ, T. et al. Conversão dos trabalhos da área contábil apresentados em congressos para publicações em periódicos. Revista Universo Contábil, Blumenau, v. 11, n. 2, p. 128-152, abr./jun. 2015.

SILVA, A. C. da; WANDERLEY, C. A. N.; SANTOS, R. dos. Utilização de ferramentas estatísticas em artigos sobre contabilidade financeira - um estudo quantitativo em três congressos realizados no país. Revista Contemporânea de Contabilidade, Florianópolis, v.1, n. 14, p. 11-28, jul./dez. 2010.

SOARES, S. V.; RICHARTZ, F.; MURCIA, F. D. R. Ranking da pós-graduação em contabilidade no Brasil: análise dos programas de mestrado com base na produção científica em periódicos acadêmicos no triênio 2007-2009. Revista Universo Contábil, Blumenau, v. 9, n. 3, p. 55-74, jul./set. 2013.

SOUZA, F. C. de. et al. Análise das IES da área de ciências contábeis e de seus pesquisadores por meio de sua produção científica. Revista Contabilidade Vista e Revista, Belo Horizonte, v. 19, n. 3, p. 15-38, jul./set. 2008.

SOUZA, F. J. V. de. et al. Perfil dos artigos sobre controladoria publicados em periódicos nacionais de contabilidade. Revista Catarinense da Ciência Contábil, Florianópolis, v. 12, Edição Especial n. 37, p. 35-50, dez. 2013.

SOUZA, J. A. e. et al. A aprendizagem organizacional gerada pela aplicação do Balanced Scorecard: Uma análise sob a ótica do modelo SECI. Revista ESPACIOS, Venezuela, v. 37, n. 19, 2016.

SOUZA, R. B. de. et al. Análise de discurso crítica e estratégia: um estudo bibliométrico e sociométrico da produção científica. Revista ESPACIOS, Venezuela, v. 37, n. 34, 2016.

VAN DER MEER-KOOISTRA, J.; VOSSELMAN, E. Research paradigms, theoretical pluralism and the practical relevance of management accounting knowledge. Qualitative Research in Accounting \& Management, v. 9, n. 3, p. 245-264, 2012.

VAN DER POLL, H.; MTHIYANE, Z. Z. F. The interdependence of risk management, corporate governance and management accounting. Southern African Business Review, v. 22, n. 1, 2018.

VENDRAMIN, E. de O. Uma contribuição ao entendimento da formação da linha de pesquisa na área de ensino contábil no Brasil. Dissertação (Mestrado em Ciências Contábeis), FEA-USP, Ribeirão Preto, 2014, 91 pg.

WALTER, S. A.; BACH, T. M. Inserção de pesquisadores entrantes na área de estratégia: análise das +relações de autoria e temas estudados no período de 1997-2010. Revista Eletrônica de Administração, Porto Alegre, v. 74, n. 1, p. 165-191, jan./abr. 2013.

WERNKE, R. Custeio baseado em atividades (ABC) aplicado aos processos de compra e venda de distribuidora de mercadorias. Revista Contabilidade \& Finanças, São Paulo, v. 16, n. 38, p. 74-89, mai./ago. 2005.

ZUCCOLOTTO, R.; SILVA, G. M.; EMMENDOERFER, M. L. Limitações e possibilidades de compreensão da utilização das práticas de contabilidade gerencial por perspectivas da teoria institucional. Revista de Administração e Contabilidade da Unisinos, São Leopoldo, v. 7, n. 3, p. 233-246, jul./set. 2010. 